\title{
Hacia una ecología política en la obra de Marx: Estado, biopolítica y medio ambiente
}

Towards a political ecology in the work of Marx: State, biopolitic and enviroment

Omar Santiago Herrera Rodríguez

Investigador independiente

San José, Costa Rica

omsahero@gmail.com

\section{RESUMEN}

El presente trabajo problematiza cómo opera el Estado en el control temporal-corporal de la vida humana y el control temporal-territorial de la naturaleza, con el objetivo principal de ofrecer un enfoque unificado que denomino ecología política y que sintetiza los programas de investigación de Robert Jessop y Paul Burkett-John Bellamy Foster, a través de la demostración de las mediaciones estatales en la fractura metabólica. Se utiliza a nivel metodológico una hermenéutica marxista, la cual busca construir una interpretación del texto cuyo éxito se encuentra en la optimización que genera al momento de acercarse a la realidad. De esta manera, se sostiene que la mejor interpretación de la obra de Marx (y de Engels) y que resulta de este trabajo, es aquella que consigue integrar en un solo programa las cuestiones ecológicas, políticas y económicas que le constituyen, evidenciando el papel que desempeña el Estado en la regulación de las contradicciones socio-metabólicas del capital a través de múltiples acciones y relaciones que se desarrollan entre actores sociales en conflicto.

Palabras clave: Estado, fractura metabólica, capital, metabolismo

\section{ABSTRACT}

The present work problematizes how the State operates in the temporal-corporal control of human life and the temporalterritorial control of nature, with the main objective of offering a unified approach that I call political ecology and that synthesizes the research programs of Robert Jessop and Paul Burkett-John Bellamy Foster, through the demonstration of state mediations in the metabolic rift. A Marxist hermeneutic is used as a method, which seeks to construct an interpretation of the text whose success is found in the optimization that it generates when approaching reality. In this way, it is argued that the best interpretation of the work of Marx (and Engels) and that results from this work, is the one that manages to integrate in a single program the ecological, political, and economic issues that constitute it, evidencing the role that the State plays in regulating the socio-metabolic contradictions of capital through multiple actions and relationships that develop between social actors in the conflict.

Keywords: State, metabolic rift, capital, metabolism 


\section{Introducción}

Durante las últimas dos décadas se ha generado y desarrollado una nueva revisión y lectura de las obras de Marx y Engels acerca de la posición que ambos pensadores tenían sobre la cuestión ecológica.

A diferencia de los trabajos pioneros en el campo que surgieron durante la década de los setenta, así como de las distintas críticas que pensadores ecológicos ajenos al marxismo plantearon sobre éste; este nuevo programa de investigación ha demostrado con éxito que, Marx y Engels desarrollaron un marco categorial fundamental para analizar los problemas ecológicos de nuestra época y a partir de ahí, han producido una ampliación de la crítica marxista a la cuestión ecológica.

No obstante, a pesar de que el ecosocialismo ha centrado su programa de investigación en una serie de problemas de suma importancia para la investigación marxista, ninguno de estos se ha relacionado o vinculado directamente en la reconstrucción del papel que desempeña el Estado en la cuestión ecológica.

Por otro lado, como ha hecho notar Robert Jessop (2008 y 2017), gran parte de las discusiones originales sobre el Estado capitalista tendieron a la definición de sus funciones o, en menor medida, a develar la relación existente entre el Estado capitalista y la economía capitalista. Sin embargo, la construcción de una ecología política sigue siendo una tarea pendiente de desarrollar por el marxismo.

De ahí que, el presente estudio centre su atención en construir algunas líneas fundamentales acerca del papel que desarrolla el Estado en el metabolismo socio-natural, identificando específicamente las operaciones y regulaciones que ejecuta éste, para el control temporal-corporal de la vida humana y el control temporal-territorial de la naturaleza.

A partir de ahí, demostraré que, a lo largo de El Capital, Marx ha puesto especial atención en la intervención del Estado en la fractura metabólica y con ello, construyó tanto los antecedentes históricos como el marco categorial necesario para una ecología política.

Sostengo además que, es necesario incorporar la mediación del Estado con el fin de entender en su totalidad el problema de la fractura metabólica; por cuanto, sin la mediación del Estado, el ascenso de la burguesía a partir del saqueo y robo de las tierras del campesinado habría desembocado en un proceso insostenible.

En este sentido, este trabajo representa un esfuerzo inicial por ofrecer una línea de unificación de dos programas de investigación de gran importancia para el marxismo: el ecosocialismo y el enfoque estratégico-relacional.

\section{Metodología}

El presente trabajo parte de un método interpretativo crítico-marxista, en el que, como señala Jameson (1989), el criterio de verdad o validez de la interpretación yace en la relación que se establece entre la realidad y la praxis social. De esto se sigue un distanciamiento significativo respecto de las lecturas positivistas que, como señala el mismo autor, invalidan una interpretación a partir de la enumeración de inexactitudes, omisiones o cuestiones no resueltas; elementos que, no son suficientes para alcanzar la invalidación de una teoría. 
Por el contrario, para Jameson (1989), sólo otra interpretación más fuerte puede derribar una interpretación ya establecida, lo que nos regresa a la arena de conflictos socio-históricos - y sus consecuentes campos de intereses, prácticas y valores diferenciados y contradictorios - de donde surgen las distintas interpretaciones que se realizan sobre un fenómeno social.

En este caso en particular, la producción de una síntesis de dos programas de investigación científica dentro de la teoría marxista: el ecosocialismo de tercera etapa y el enfoque estratégicorelacional, permite construir a través de la identificación de sus puntos críticos, campos y temas comunes y sus vacíos conciliables, una mejor interpretación de las discusiones desarrolladas por Karl Marx en torno a la cuestión ecológica y el Estado capitalista.

Ahora bien, esta hermenéutica no queda reducida al texto ni al contexto de la obra como tal, sino que, considera y aprehende el conjunto de relaciones socio-históricas que determinan tanto a la obra como a su acercamiento, los cuales se encuentran constituidos y traspasados por los conflictos de clases sociales, en cuanto elemento constitutivo de toda lectura marxista de la historia.

\section{Desarrollo}

Este trabajo consigue una expansión del campo temático desarrollado por los programas de investigación marxista del ecosocialismo y el enfoque estratégico-relacional, al incorporar la mediación del Estado en la crítica ecológica marxista.

De esta manera, se obtiene un primer acercamiento a una teoría unificada de ecología política marxista, a través del desarrollo de dos ejes de discusión: el control temporal-corporal de la vida humana y el control temporal-territorial de la naturaleza.

Con esto se dota a la crítica de la crisis ecológica de un componente sustantivo y fundamental para una comprensión totalizadora para el abordaje de los problemas a los que se enfrenta: el lugar que ocupa el Estado y el campo de la política en la constitución y reproducción de dicha crisis, pero también, en su contención y posible reversión según sea la correlación de fuerzas en disputa y las estrategias que los actores sociales construyan de acuerdo a coyunturas.

\subsection{Metabolismo y fractura metabólica}

El concepto de metabolismo juega un papel fundamental en el desarrollo teórico y maduración de la obra de Marx. Su acercamiento a los economistas políticos ingleses le permitió dar un salto comprensivo respecto de sus primeros escritos de economía en la década de los cuarenta.

Por ejemplo, en los Manuscritos de París, encontramos una incipiente comprensión del problema: "El trabajador no puede producir nada sin la naturaleza, sin el mundo exterior sensible. Ésta es la materia en que se realiza su trabajo, en que éste actúa, a partir de la cual y con la cual produce" (Marx, 2012, 486). Vemos cómo, desde su juventud, Marx comprende el carácter de necesidad que la naturaleza desempeña para el trabajador, puesto que, sin ella, no es posible producir nada.

Por esta razón, Marx muestra cómo el proceso de enajenación del producto del trabajo representa para el trabajador una desgracia, puesto que, mientras enriquece cada vez más al capitalista, empobrece en proporción inversa cada vez más al trabajador, de forma que, la satisfacción directa obtenida a través del vínculo con la naturaleza se pierde. 
Sin embargo, fue a partir de la década de los cincuenta, principalmente con la lectura de los trabajos de Justus von Liebig y de James Anderson (Foster y Magdoff (1998) y Foster (1999)) sobre la degradación de los suelos ocasionada por los avances industriales y de la ciencia química que era empleada en la agricultura capitalista, lo que permitió a Marx adentrarse en la explicación del metabolismo y la fractura metabólica. Esto aunado a su asiduo estudio de los economistas políticos ingleses.

Saito (2014) explica que, durante su exilio en Londres en el año de 1849, Marx realizó diversos apuntes (Los Cuadernos de Londres) a propósito de la crítica sobre la ley de rendimientos decrecientes de David Ricardo. El pensador inglés desarrollaba la siguiente formulación del problema: hay un número limitado de buenos suelos para la agricultura, esto obliga a desarrollar cultivos en suelos menos fértiles, por lo que es necesario emplear más trabajo para sostener la producción de alimentos; sin embargo, esto conduciría en consecuencia al incremento de los costos de los alimentos.

Para este momento, según Saito (2014), Marx había leído en 1845: A Calm Investigation of the Circumstances that have led to the Present Scarcity of Grain in Britain de James Anderson, en la que se planteaba la posibilidad de incrementar la fertilidad de los suelos; por lo que la forma en la que David Ricardo planteaba la cuestión no le resultaba satisfactoria.

En 1851 tuvo acceso a otra obra del mismo autor: Inquiry into the Causes that have hitherto retarded the Advancement of Agriculture in Europa, notando en ella que hay infinitos tipos de suelo, pero que, éstos podrían ser manipulados y mejorados a partir del uso de fertilizantes. Su estudio de la química y otras ramas científicas continuó durante todos esos años.

También tuvo oportunidad de estudiar los trabajos de John Morton y Henry C. Carey, quienes se ocuparon respectivamente de la productividad de las tierras y los problemas de la producción en Estados Unidos debido al uso de grandes maquinarias, mostraron cómo se extraían muchos recursos del suelo, pero no se retornaba nada a éste.

En la redacción de El Capital, los conocimientos adquiridos durante esa época aparecen de forma notoria al desarrollar su concepto del metabolismo, el cual recupera la noción inicial de la relación ser humano-naturaleza, pero ahora comprendida desde una interacción recíproca entre ambos elementos de la unidad metabólica, la cual se encontraba mediada por las condiciones del modo de producción capitalista:

Con la preponderancia incesantemente creciente de la población urbana, acumulada en grandes centros por la producción capitalista, esta por una parte acumula la fuerza motriz histórica de la sociedad, y por otra perturba el metabolismo entre el hombre y la tierra; esto es, el retorno al suelo de aquellos elementos constitutivos del mismo que han sido consumidos por el hombre bajo la forma de alimentos y vestimenta, retorno que es condición natural eterna de la fertilidad permanente del suelo. Con ello destruye, al mismo tiempo, la salud física de los obreros urbanos y la vida intelectual de los trabajadores rurales (Marx, 2017, p. 584).

En este fragmento se condensan todos los elementos que caracterizan el metabolismo y la fractura metabólica: el metabolismo es la acción de intercambio recíproco entre los seres humanos y la naturaleza, no obstante, dicho intercambio demanda ciertas condiciones de sostenibilidad, en 
la medida que, ocupa necesariamente del retorno suficiente de compuestos materiales para la recuperación efectiva de la naturaleza (los suelos, en este caso), posterior a su transformación a partir del trabajo efectuado por los seres humanos.

El modo de producción capitalista altera de forma radical el metabolismo ser humano-naturaleza en la medida que, separa a los trabajadores de los medios de producción, empobreciendo la vida y la salud de los trabajadores urbanos y empobreciendo y embruteciendo la vida de los trabajadores rurales.

En este sentido, podemos compartir la lectura que realiza Mészáros (2011) sobre el concepto de metabolismo, al definirlo como el marco de referencia que permite comprender la totalidad de las determinaciones socio-ontológicas, desde aquellas relacionadas con los procesos materiales directos, hasta las prácticas intelectuales más mediadas.

El metabolismo comprende el marco referencial de análisis de todas las determinaciones sociales, en cuanto, es la unidad original y transhistórica de todas las determinaciones socio-ontológicas, puesto que, la relación entre los seres humanos y la naturaleza aparece en todas las formaciones sociales, desde las más primitivas hasta las sociedades tecnológicamente más desarrolladas.

De este modo, el metabolismo constituye una condición inherente y fundante de nuestra especie, pues, a través de éste, nos relacionamos no sólo con la naturaleza, sino que, también nos relacionamos con los otros miembros de la especie. Por ello, la fractura ocasionada por el capitalismo posiciona una contradicción fundamental y radicalmente peligrosa para la supervivencia de la humanidad completa: "La producción capitalista, por consiguiente, no desarrolla la técnica y la combinación del proceso social de producción sino socavando, al mismo tiempo, los dos manantiales de toda la riqueza: la tierra y el trabajador" (Marx, 2017, p. 585).

Como señalan Burkett (1999) y Williams (2010), las sociedades capitalistas son insostenibles, porque, mientras la relación sociedad-naturaleza demanda límites cuantitativos, la forma valor de la riqueza exige cada vez mayores cantidades de materias y energías; en otras palabras, la naturaleza de la producción de capital vuelve la expansión económica un imperativo innegociable e imparable.

El impulso al lucro y el enfoque cortoplacista centrado en las ganancias inmediatas hacen del capitalismo un sistema ecológicamente insostenible, al mismo tiempo que, un medio de destrucción de las fuerzas y condiciones vitales de los trabajadores. Sin embargo, profundicemos más en lo que significa la fractura metabólica.

De acuerdo a Burkett y Foster (2016), cuando Marx planteó la cuestión del campesinado su preocupación se centró en el aislamiento que sufrían los campesinos respecto de los centros urbanos y con ello, su poca o nula posibilidad de acceder a los bienes y servicios que se encontraban concentrados en los segundos espacios, lo cual ocasionaba una precarización material y espiritual del campesinado.

Más todavía, como señalé con anterioridad mediante un fragmento de El Capital, Marx encuentra que la fractura metabólica ha sido ocasionada a partir del proceso de división entre el campo y la ciudad, tal como explica Foster (2000): 
Insistir en que la sociedad capitalista a gran escala ha creado esta fractura metabólica entre los seres humanos y el suelo era considerar que se habían violado las condiciones de la sostenibilidad impuestas por la naturaleza. "La producción capitalista -observa Marx- sólo repara en la tierra después de que sus efectos la hayan agotado, y tras haber devastado sus cualidades naturales". Además, esto podía verse no sólo en relación con el suelo, sino también en la relación de antagonismo existente entre la ciudad y el campo. Para Marx, como para Liebig, el hecho de que no se le devolvieran al suelo los nutrientes que se habían sacado de él en forma de alimentos y de fibras tenía su contrapartida en la contaminación de las ciudades y en la irracionalidad de los modernos sistemas de alcantarillado (p. 252).

Foster recoloca el acento en uno de los puntos ciegos del proceso de modernización capitalista: la irracionalidad de la lógica del crecimiento urbano y su carácter altamente destructivo en contra de la naturaleza y de las vidas de los seres humanos que viven en las urbes.

La ciudad, como lo señala Saito (2017), destruye la vida y la salud humana. Esto en realidad hace recordar las palabras de Marx (2012) en los Manuscritos de París, cuando señalaba que, el trabajador bajo la dominación de la lógica del capital se siente libre tan solo en sus funciones animales y por el contrario, en sus funciones sociales se siente oprimido.

Ahora bien, ni siquiera en la reducción del humano a su mera animalidad las afectaciones de la vida en la ciudad se detienen, por el contrario, el modo de producción capitalista las ha acelerado. Pero para entender el extraordinario alcance que tiene este enfoque de lectura de la obra de Marx, es necesario incorporar el papel del Estado.

\subsection{Origen de la fractura metabólica y la intervención del Estado}

En el capítulo La llamada "acumulación originaria”, Marx (2017) conduce su análisis a un nivel de mayor concretización en torno a la cuestión del surgimiento del capital, mostrando ahora cómo este proceso se realizó al lado de "la conquista, el sojuzgamiento, el homicidio motivado por el robo: en una palabra, la violencia” (p. 807), y añade más adelante: “El derecho y «el trabajo» fueron desde épocas pretéritas los únicos medios de enriquecimiento” (p. 808).

Es decir, Marx es claro en la imbricación existente entre economía y política o dicho de otro modo, entre las formas de explotación de la naturaleza y los seres humanos y las formas de dominación y represión para legitimar y sostener la explotación, como señala Kohan (2013).

Aunque Marx (2008a) no consiguió concretar la cuestión del vínculo entre economía y política, cuya abordaje específico proyectó en uno de los seis tomos que conformarían el proyecto de El Capital, Osorio (2012) y Kohan (2013) demuestran que su aparente división en esta obra corresponde a un asunto de método expositivo y no del marco categorial de análisis. Cuando Marx redacta El Capital comienza por el análisis de la mercancía y de las categorías económicas más simples, pero esto ocurre no porque Marx desconsiderara el papel de las relaciones de poder o del Estado en la producción de mercancías o en la economía en general, sino porque su método de exposición parte del momento más abstracto del fenómeno hasta su concretización a través de la incorporación de sus relaciones y determinaciones.

De hecho, Marx enlazará los tres procesos que nos interesa aquí mostrar: el origen de la fractura metabólica, el posicionamiento de la producción de capital como modo de producción 
predominante y el Estado como mediación del proceso de violencia que significó la fractura metabólica. Me permito una cita extensa para ilustrar lo anterior:

Aunque el poder real - él mismo un producto del desarrollo burgués - en su deseo de acceder a la soberanía absoluta aceleró violentamente la disolución de esas mesnadas, no constituyó, ni mucho menos, la única causa de esta. Por el contrario, el gran señor feudal, tenazmente opuesto a la realeza y al Parlamento creó un proletariado muchísimo mayor, al expulsar violentamente a los campesinos de la tierra, sobre la que tenían los mismos títulos jurídicos feudales que él mismo, y al usurparles las tierras comunales. En Inglaterra, el impulso directo para estas acciones lo dio particularmente el florecimiento de la manufactura lanera flamenca y el consiguiente aumento en los precios de la lana. Las grandes guerras feudales habían aniquilado a la vieja nobleza feudal; la nueva era hija de su época, y para ella el dinero era el poder de todos los poderes (Marx, 2017, p. 812).

Aunque no de forma directa, trabajos de inspiración marxista como los de Jessop (2017a) y Quastel (2016), han mostrado que el Estado juega un papel central en la configuración de la naturaleza como el ejemplo aquí expuesto. Por supuesto, esta idea va más allá del empleo de la violencia directa, como mostraré más adelante en otras referencias.

En este momento, particularmente Marx apunta a una serie de condiciones que confluyeron entre los siglos XVI-XVIII en Inglaterra: las luchas entre señores feudales, el decaimiento del antiguo régimen monárquico en manos de una aristocracia terrateniente, la expulsión de los campesinos y los soldados que pasaron a conformar una enorme masa de proletarios libres y el crecimiento de la manufactura; todos estos procesos reunieron las condiciones para una transición en la que una nueva clase social ascendía en detrimento no sólo de la vieja clase dominante, sino del campesinado inglés que, ahora se encontraba sin sus tierras, es decir, sin sus medios de subsistencia.

Por supuesto, Marx (2017) describe estos acontecimientos como un "proceso de expropiación violenta de las masas populares" (p. 814), de sus tierras y sus bienes. Ahora bien, la destrucción del viejo orden demandó la construcción de uno nuevo y para ello, su legitimación frente a toda la población.

Aunque Marx señala que, este periodo estuvo marcado por actos individuales de violencia por parte de la oligarquía inglesa en contra del campesinado y el clero, ya para el siglo XVIII y ante la derrota de la vieja legislación que nunca pudo detener este proceso, la burguesía inglesa consolidada en el poder económico se apropió de la legislación, con el objetivo de legitimar e institucionalizar sus acciones:

El progreso alcanzado en el siglo XVIII se revela en que la ley misma se convierte ahora en vehículo del robo perpetrado contra las tierras del pueblo, aunque los grandes arrendatarios, por añadidura, apliquen también sus métodos privados menores e independientes (Marx, 2017, p. 818).

No se trata del uso de la ley y en consecuencia del Estado, como un instrumento de la nueva clase dominante en ascenso en contra de las antiguas clases dominantes, el viejo campesinado y el nuevo proletariado; sino de la ausencia, en la correlación de fuerzas, de una clase con suficiente organización y poder para detener o tensionar el avance de la burguesía inglesa. Esta forma 
de posicionar el problema, muestra cómo el Estado es configurado mediante el entramado de relaciones y estrategias que las distintas clases sociales establecen coyunturalmente (Jessop, 2008 y 2017).

En el caso en cuestión, la asimetría de poderes dada por la posesión de la tierra, la manufactura y el dinero, permite a la oligarquía estabilizar y legalizar sus acciones de violencia a través del Estado; sin que esto signifique, como aclara Marx, que ella misma deje de ejercer violencia de forma directa, aunque en menor medida, sobre las masas proletarizadas.

Ahora bien, para este momento, se trataba entonces de hacer del robo de la propiedad de otros y de la violencia prácticas legalmente permitidas. Las razones para que este proceso ocurra fueron el objeto central de los análisis del jurista ruso Evegny Pasukanis (1976) durante la primera mitad del siglo XX, quien sintetizó mediante tres preguntas el problema central de lo que años después el enfoque derivacionista denominaría como particularización del Estado.

Las preguntas eran: 1) ¿por qué la dominación de clase no continúa siendo lo que es, a saber, la sumisión de una parte de la población a la otra?, 2) ¿por qué el aparato de coacción estatal no se constituye como aparato privado de la clase dominante? y 3) ¿por qué se separa aquél de esta última y reviste la forma de un aparato de poder público impersonal, separado de la sociedad?

Por su parte, Jessop (2008) coincide con el planteamiento del problema del jurista soviético, enfatizando en que, el capital posee una incapacidad intrínseca para reproducirse por sí mismo, por lo que demanda de una serie de respaldos extraeconómicos. De modo que, el Estado funge como el responsable, por un lado, de garantizar una serie de condiciones para la valorización del capital y la reproducción de la fuerza de trabajo; así como, de mantener la cohesión social en una formación social pluralista y dividida, ya sea, por conflictos entre clases sociales o por conflictos entre bloques a lo interno de una misma clase por la hegemonía.

Esta cohesión política necesaria en sociedades escindidas por diferencias y conflictos de clase demanda, según Hirsch (2005), que el uso de la fuerza o la violencia no pueda realizarse de forma directa, sino que, el Estado se presente a sí mismo, inmediatamente, como un ente particularizado de los conflictos de clase, una especie de árbitro neutral; en lugar, de encontrarse permanente y contingentemente constituido por la relacionalidad entre actores sociales.

De lo contrario, el tipo de sociedad capitalista no podría asentarse ni desarrollarse, en la medida que requeriría de manera continua el uso directo de la violencia contra los trabajadores desposeídos de los medios de producción. Históricamente sabemos que, como señala Hobsbawm (2006) y cinco siglos antes había considerado Maquiavelo (2012), ningún tipo de sistema sociopolítico puede sostenerse de forma exclusiva mediante el uso de la fuerza y la violencia.

Es esta aparente exterioridad del Estado respecto de los conflictos entre clases lo que contribuye a la cohesión de las sociedades capitalistas. Precisamente, Marx observa cómo la burguesía inglesa requería de una forma política que se correspondiera con su dinámica económica, con el fin de institucionalizarla y legitimarla.

En otras palabras, para Marx, el Estado capitalista desempeña un papel fundamental en el origen, desarrollo y consolidación de la fractura metabólica, por cuanto sostiene la conflictividad social 
generada por la expulsión a gran escala de los campesinos de sus tierras y la apropiación privada de las mismas por esta nueva clase social.

Las formas de regulación del conflicto son variadas. Marx (2017) muestra que, ante el excedente de población trabajadora desempleada a finales del siglo XV y durante todo el siglo XVI en toda Europa Occidental, comenzaron a gestionarse leyes contra la vagancia: "A los padres de la actual clase obrera se los castigó, en un principio, por su transformación forzada en vagabundos e indigentes" (Marx, 2017, 828).

Mientras ancianos e incapacitados, dice Marx, recibían una licencia de mendicidad, las personas que poseían la capacidad de trabajar, pero no lo hacían, eran castigados de diversas formas: durante el siglo XV podían serlo mediante su esclavización por parte del denunciante, también podía cortárseles media oreja o azotárseles. En el siglo XVII, bajo el gobierno de Luis XVI se les encarcelaba y enviaba a las galeras a trabajar. De esta manera, dice Marx (2017):

...la población rural, expropiada por la violencia, expulsada de sus tierras y reducida al vagabundaje, fue obligada a someterse, mediante una legislación terrorista y grotesca y a fuerza de latigazos, hierros candentes y tormentos, a la disciplina que requería el sistema del trabajo asalariado (Marx, 2017, 830-831).

Tenemos la descripción del tránsito a una sociedad disciplinaria y reguladora de la bíos: de los cuerpos, de sus tiempos y de las relaciones entre los seres humanos. Es evidente que la vida del campo posee ritmos distintos a la vida en la ciudad, de modo que, los nuevos dominadores necesitaban disciplinar a las personas a amplias jornadas de trabajo, bajo condiciones precarias, sin descanso y con tiempos regulados para sus necesidades biológicas más elementales.

Al mismo tiempo, para evitar la organización del proletariado, Marx (2017) muestra cómo desde el siglo XIV y hasta 1825, todas las coaliciones obreras eran consideradas como un delito grave:

Por el decreto del 14 de junio de 1791, declaró todas las coaliciones obreras como «atentatorias contra la libertad y contra la Declaración de los Derechos del Hombre», punibles con una multa de 500 libras y privación de la ciudadanía activa por el término de un año. Esa ley, que con medidas policíaco-estatales encauzó coercitivamente, dentro de límites cómodos al capital, la lucha competitiva entre este y el trabajo, sobrevivió a revoluciones y cambios dinástico (Marx, 2017, p. 835).

Ante las dificultades de organizarse, los trabajadores fueron también sometidos tanto a arbitrariedades de los patronos sobre el pago de sus salarios, como a las legislaciones vigentes que mantenían los niveles salariales en cantidades minúsculas e insuficientes para su sostenibilidad vital y la de sus familias.

La falta de posibilidades y capacidad del proletariado naciente para organizarse se refleja en la importante unilateralidad con que operaba el Estado. La abismal diferencia en la correlación de fuerzas entre actores sociales con intereses contrapuestos es lo que hace parecer que el Estado funciona como un instrumento de la burguesía; sin embargo, conforme se agudiza el conflicto entre clases y la correlación de fuerzas se equilibra, se aprecia mejor el carácter relacional del Estado tal como ha sido analizado por Poulantzas (1986) en primer lugar y posteriormente por Jessop (2017), en la medida que la materialidad que cobra el Estado (dígase, sus instituciones, sus funciones, sus acciones) se encuentra determinada por este conflicto. 
Tomará años para que la nueva clase proletaria consiga organizarse en medio de las adversidades y tensar con ello las relaciones de explotación y dominación impuestas por el capital-Estado burgués. Sin embargo, ante estos peligros, interesa abordar los objetivos centrales de este trabajo: cómo el Estado regula las determinaciones espacio-temporales de la vida humana y el medio ambiente.

Hemos visto ya en términos generales cómo intervino en la génesis de la fractura metabólica y la acumulación primitiva del capital. Ahora nos interesa avanzar a tareas más concretas.

\subsection{Marx: el padre biológico de la biopolítica}

Sabemos que el concepto de biopolítica es acuñado por el pensador francés Michel Foucault para denominar un proceso cuyo surgimiento data del siglo XIX y representa: "un ejercicio del poder sobre el hombre en cuanto ser viviente, una especie de estatización de lo biológico o, al menos, cierta tendencia conducente a lo que podría denominarse la estatización de lo biológico" (Foucault, 2001, p. 217).

Para Foucault, el Estado en el siglo XIX dio un giro en la manera que ejercía su poder: mientras el viejo derecho de soberanía hacía morir y dejaba vivir; el nuevo derecho, el del Estado moderno, hacía vivir y dejaba morir. Esto se debía a la producción e introducción de nuevos saberes y tecnologías asociadas al control de los procesos vitales de la población:

La nueva tecnología de poder no tiene que vérselas exactamente con la sociedad (o, en fin, con el cuerpo social tal como lo definen los juristas); tampoco con el individuo/ cuerpo. Se trata de un nuevo cuerpo: cuerpo múltiple, cuerpo de muchas cabezas, si no infinito, al menos necesariamente innumerable. Es la idea de población. La biopolítica tiene que ver con la población, y ésta como problema político, como problema a la vez científico y político, como problema biológico y problema de poder, creo que aparece en ese momento (Foucault, 2001, p. 222).

Los problemas de natalidad, mortalidad y longevidad del siglo XVIII dan los primeros objetos de análisis e intervención de la biopolítica. Es la época de la estadística y la demografía; un poco más tarde, de la introducción de instituciones asistenciales, de los mecanismos de seguros y ahorro, de seguridad, etc. También de la intervención sobre la salud y la relación del ser humano con su entorno, como sucede con el control de epidemias, la higiene y los problemas ocasionados por la ciudad.

Estos cambios demuestran, según Foucault, el interés del Estado por controlar cada vez más la vida y no la muerte:

Ahora bien, cuando el poder es cada vez menos el derecho de hacer morir y cada vez más el derecho de intervenir para hacer vivir, sobre la manera de vivir y sobre el cómo de la vida, a partir del momento, entonces, en que el poder interviene sobre todo en ese nivel para realzar la vida, controlar sus accidentes, sus riesgos, sus deficiencias, entonces la muerte, como final de la vida, es evidentemente el término, el límite, el extremo del poder. Está afuera con respecto a éste: al margen de su influencia, y sobre ella, el poder sólo tendrá un ascendiente general, global, estadístico. El influjo del poder no se ejerce sobre la muerte sino sobre la mortalidad. Y en esa medida, es muy lógico que la muerte, ahora, esté del lado de lo privado, de lo más privado (Foucault, 2001, p. 224). 
Por esta razón es que Foucault encuentra que el Estado funge como un mecanismo que genera un equilibrio global y no un adiestramiento individual. Para esto, crea una serie de mecanismos reguladores y de disciplinas-saberes que recaen en la población: sistemas de seguros contra enfermedad, vejez y muerte, reglas de higiene, sistemas de salud, escolaridad, etc. Osorio (2012) reconstruye las bases del biopoder a través de la lógica del capital:

El acontecimiento fundamente en este giro histórico se ubica en los procesos que propiciaron la violenta y masiva separación de los trabajadores de los medios de producción y de los medios de subsistencia y su conformación en tanto capital, reseñados por Marx en la llamada «acumulación originaria» (p. 87).

Al ocurrir esta fractura se asienta el camino para la universalización de la forma mercancía como relación fundamental de todas las relaciones sociales. En la compra y venta de una mercancía, señala Osorio, no se juega solamente un intercambio de cosas, sino, de la existencia misma de los trabajadores, por cuanto, quien entrega la mercancía vendida está vendiendo su propia existencia, su fuerza de trabajo, su cuerpo vivo.

Después, el trabajador velará por re-apoderarse de su capacidad de trabajo a través del dinero que recibe en forma de salario. En esta dinámica se encuentra el fundamento del poder del capital sobre la vida humana: la reproducción de la vida humana de la mayor parte de la población se encuentra condicionada por la obtención del salario. Así, la lógica del capital encierra y determina la vida misma.

Osorio (2012) se encarga de exponer además dos formas en que el capital ejerce este biopoder. Las expondré brevemente para dar paso a una ampliación y profundización de las mismas. La primera de ellas es denominada por él vida infrahumana, y refiere a la explotación que sufren los trabajadores y que termina por agotar sus energías y su vida. Son numerosos los casos que documenta Marx a propósito de la muerte o enfermedad de niños, niñas, mujeres y hombres en las fábricas inglesas del siglo XIX. Hoy no existe mayor diferencia al respecto en diversas partes del mundo.

El capital controla la temporalidad de los trabajadores a partir de la asignación de una vida útil la cual supone el valor diario de la vida humana en términos de los alimentos, vestuarios y demás bienes necesarios para la reproducción vital de los trabajadores. Esto conlleva, en contraparte, a la universalización de una formación social que produce una serie de mercancías destinadas a la venta y consecuente consumo de quienes pueden adquirirlas mediante el dinero.

Ahora bien, Osorio (2012) explica que, hay momentos en los que el capitalista reduce el salario por debajo del valor de los bienes indispensables para la reproducción de la vida de los trabajadores. Con ello, desplaza o transfiere dicha cantidad al fondo de acumulación. Esto es la vida infrahumana.

La siguiente es la vida desfalcada. Esta remite directamente a los conceptos de plusvalía absoluta y plusvalía relativa (aunque estos no son considerados por el autor), pues describe la degradación de la vida humana a causa de la prolongación o intensificación de la jornada de trabajo.

El capitalista, con el objetivo de incrementar sus ganancias, no encuentra reparos en incrementar el desgaste vital de sus trabajadores por medio del uso de alguno de los dos métodos señalados, 
sea por prolongación o por intensificación de la jornada de trabajo. Por ello, el trabajador reduce sus posibilidades de recuperación y regeneración vital e incrementa sus posibilidades de contraer enfermedades, lesiones discapacitantes, incapacidades, etc.

Recientemente, la UNI Global (2021), una alianza compuesta por sindicatos de 22 países, publicó el informe The Amazon Panopticon, donde precisamente detallaban la forma en que, a través de medios tecnológicos como el uso de brazaletes, algoritmos, sistemas de vigilancia, entre otros, la empresa de Jeff Bezos (el hombre más rico del mundo) buscaba que los trabajadores trabajasen cada vez más rápido mediante la vigilancia permanente de sus movimientos, con el fin de que las entregas se hicieran en plazos cada vez más cortos; afectando la salud principalmente de mujeres y mujeres embarazadas debido al control de tiempos para ir al baño.

Ejemplos como éste muestran las consecuencias de lo que un teórico foucaultiano como ByungChul Han (2012) denominó sociedad del cansancio, donde los trabajadores llegan a sentirse incluso responsables por no rendir lo suficiente incurren en prácticas dañinas como el doparse mediante medicamentos para incrementar su capacidad de trabajo. En la contraparte, por supuesto, se encuentra la permanente amenazada de ser despedido o, cuando se trata de contratos temporales, de no tener la oportunidad de un nuevo contrato, poniendo en riesgo la supervivencia individual del trabajador.

Aquí tenemos una descripción de la intervención directa del capital en la regulación de la temporalidad y corporalidad de la vida humana; no obstante, dicha intervención no se realiza al margen del Estado, sino que se encuentra mediatizada por éste, ya sea a través de su legalidad o ilegalidad.

Por ejemplo, la reducción de la jornada de trabajo a partir de las luchas obreras del siglo XIX supuso la creación de una legislación que regulaba y delimitaba las posibilidades del capital para determinar de manera directa la vida humana de las personas por un lado, pero también, condujo a la búsqueda de alternativas para la extracción de mayor plusvalía mediante la incorporación de máquinas que intensificaran el empleo de fuerza de trabajo y se produjera la misma cantidad de ganancias o una mayor, pero dentro de los límites de lo normado, como bien lo describió Marx (2017) a lo largo del primer tomo de El Capital.

Contemporáneamente, aunque en diversos países existe la jornada mínima de trabajo, también se han incorporado otras formas flexibles que permiten incorporar de manera legal cambios a la jornada mínima o en las formas de contratación; por ejemplo, a través de la concentración de más horas de trabajo en unos cuantos días a cambio de más días de descanso o mediante la subcontratación, tercerización e informalización del trabajo, las cuales, generan una cadena de precarización y vulnerabilidad de las condiciones de trabajo de los trabajadores, como bien ha sido demostrado por Antunes (2009 y 2015). Ejemplo paradigmático de esto son las nuevas formas de contratación estimuladas por plataformas de servicios digitales como Uber.

En todos los casos anteriores, existe la falsa suposición de que al trabajador se le paga el equivalente invertido a su tiempo y fuerza de trabajo, de manera que, el intercambio desigual entre el patrono y el trabajo aparece revestido legalmente como un intercambio justo. 
En el Estado se cristalizan luchas de clases a través de legislaciones, sin embargo, esto no deviene en quietud, ya que los capitalistas desarrollan alternativas más o menos legítimas para continuar con la extracción de plusvalor, mientras que los trabajadores deben permanecer en una constante lucha con el fin de no experimentar retrocesos políticos, debido a que la lógica de la acumulación del capital empuja a la destrucción de sus propios avances políticos.

Al respecto, es importante señalar que, al ser el Estado una condensación de relaciones y estrategias contingentes y conflictuadas de clases sociales o de distintos actores que conforman bloques de clase, puede producir tendencias y contra-tendencias a la lógica de acumulación progresiva y extensiva del capital sobre la vitalidad humana y el medio ambiente.

Ahora bien, el Estado también desempeña una función político-social fundamental para la reproducción del capital, la cual por supuesto se encuentra en tensión por las luchas sociales de los trabajadores. Jessop (2008) señala:

Un área en la que el carácter inevitablemente político de la intervención económica y social aparece de forma especialmente clara es la de la reproducción de la fuerza de trabajo como mercancía ficticia, pues en el tipo de Estado capitalista ésta se relaciona también con el derecho de los ciudadanos a la subsistencia (p. 51).

El capitalista necesita desgastar lo máximo posible al trabajador con el fin de extraer de él todo el plusvalor posible, ya sea por la ampliación o la intensificación de la jornada de trabajo a través de la inversión en capital fijo. Al mismo tiempo, si solo de él dependiera, reduciría al máximo posible los gastos por concepto de capital variable, con el fin de aumentar sus ganancias.

Sabemos que, los trabajadores han luchado históricamente por la reducción de la jornada de trabajo, por el establecimiento de un salario mínimo y por el incremento de sus salarios. Pero la garantía de estas condiciones no es suficiente para su reproducción social y esto sucede porque, los seres humanos no son simples animales, sino que consumen una serie de bienes y servicios socialmente producidos para satisfacer sus necesidades sociales y las de sus familias.

Por esta razón, la disputa también se ha dado en el marco de otras reivindicaciones obreras: la seguridad social, la educación, entre otros. No obstante, si el capitalista asumiera el costo de todos estos bienes y servicios vería reducidas sus ganancias considerablemente. El traslado de estos gastos al Estado permite al mismo tiempo distribuir el valor de los mismos entre todos los individuos mediante la recaudación de impuestos. Aunque, supongamos que, los impuestos son proporcionales a los ingresos de cada uno de los individuos, el capitalista paga los suyos a través de la explotación de sus trabajadores.

De este modo puede mantener el incremento de sus ganancias, al mismo tiempo que, se aprovecha la cualificación y sostenibilidad de su mano de obra a través de los bienes y servicios que brinda el Estado. Como señala Castel (1997), en el caso de la seguridad social, ésta condujo a una reformulación de la relación propiedad privada-trabajo; en la medida que, no abolió la oposición propietario/no propietario, sino que, yuxtapuso a la propiedad privada, la propiedad social, haciendo que, todos aquellos que no tuvieran propiedad privada no carecieran de seguridad, a través de la mediación del trabajo y del Estado. 
En el caso de la educación es evidente que, la cualificación que brinda permite formar trabajadores con mayores capacidades y conocimientos para asumir sus tareas; esto se traduce en la posibilidad de trabajar más y mejor en menos tiempo; a la vez que, según el oficio o profesión, conlleva al ahorro en los gastos por concepto de compra de las materias primas necesarias. Pongamos un ejemplo: un trabajador manual de la industria automotriz al realizar estudios técnicos, no sólo mejora su capacidad de trabajo y por tanto, incrementa su velocidad; sino que, al obtener mayor grado de pericia en su trabajo, desperdiciará menos materiales para la realización de su trabajo.

Por otro lado, los trabajadores obtienen otros medios indispensables para su reproducción, en otras palabras, para el alargamiento de su tiempo vital y la sostenibilidad de sus cuerpos ante el desgaste físico y espiritual de la jornada de trabajo. La atención de sus enfermedades o accidentes, la obtención de conocimientos para el desarrollo de sus oficios y la posibilidad de sostenerse socio-económicamente cuando el capital haya acabado con sus fuerzas físicas; son también el resultado de luchas.

En el mismo frente, el Estado asume la asistencia de, al menos, una parte de la amplia masa de población desempleada con el fin de reducir los focos de conflicto y violencia. La asistencia social se convierte en un medio de apaciguamiento de los sectores marginales de la sociedad que no tienen los medios de transferencia económica para garantizar su aseguramiento, con el fin de mantener el equilibrio social.

De esta manera también, mantiene con vida - aunque precaria - al ejército de reserva necesario para atemorizar a la población empleada. El peligro constante e inminente de verse excluido del mercado laboral se convierte en una de las herramientas más poderosas del capitalista para disciplinar a los trabajadores y prevenir su organización.

Lo anterior por el proceso de separación originario de los trabajadores de los medios de su producción. Con esto volvemos al problema fundante del capitalismo: constituye una idea de libertad formal de los seres humanos, al mismo tiempo que, en la realidad, la mayor parte de éstos se ve en la obligación de soportar la degradación y la explotación, debido a que, no posee los medios para poder satisfacer sus necesidades sin la necesidad de que medie el capitalista para ello.

La expropiación de la tierra inauguró una nueva forma de control, regulación y dinamización de los tiempos humanos y de sus cuerpos. Sus consecuencias son tan desastrosas para la vida de la mayor parte de la población que, resulta necesaria la intervención de un aparente agente exterior al conflicto fundamental de clase, con el fin de garantizar grados variables de cohesión política, mediante el empleo de la violencia directa o de otros medios.

No obstante, la permanencia de la contradicción capital/trabajo se traduce en una interminable lucha de clases donde se disputa la ampliación insaciable del capital y la sobrevivencia humana. Por otro lado, sabemos que no solamente se encuentra en disputa la vida humana, sino también, la otra fuente de vida del capital: la naturaleza. Sobre esto trabajaré en último apartado de este estudio. 


\section{Naturaleza y Estado}

En el primer apartado de este trabajo, a propósito de la fractura metabólica, fue expuesto que el descubrimiento y empleo de nuevos químicos en la agricultura industrial trajo consigo un cambio radical en los suelos, en la medida que alteró sus tiempos de recuperación.

En la actualidad podemos decir lo mismo de los ciclos de vida de los frutos, los cuales son alterados a través de las variaciones genéticas que se hacen de éstos, con el fin de incrementar su calidad y facilidad de comer. Así, por ejemplo, se producen alimentos sin semillas y de esta forma, el fruto no retorna al ciclo reproductivo de la naturaleza, sino que es acabado mediante un único consumo.

El papel del Estado respecto a las variaciones temporales de los alimentos y los suelos es tanto directo, como indirecto. Directo, porque los Estados financian programas de investigación en la materia, a través de centros de enseñanza superior o centros de investigación dedicados a áreas híper-especializadas del conocimiento como la biotecnología, la química industrial, la ingeniería agrícola o la tecnología de alimentos.

Indirecto, porque en estos mismos lugares se forman a los intelectuales que después ocuparán los puestos de investigación y administración de las empresas privadas para el desarrollo de nuevas tecnologías o para la ejecución de las mismas para la producción de bienes de consumo.

En los primeros trabajos de Liebigy Anderson leídos por Marx (y en realidad, desde los experimentos de Gregor Mendel), se encontraba ya el germen de la industria alimenticia. Hablamos no sólo de la transgresión de los ciclos y límites del suelo para su regeneración, sino de la transgresión completa de los alimentos: alargamos su tiempo de putrefacción, interrumpimos su reproducción natural, diseñamos especies más resistentes a plagas, al mismo tiempo que dichas plagas se vuelven más resistentes y, por ende, representan un problema mayor para la alimentación de la mayor parte de la población mundial.

Sin embargo, el problema temporal de mayor envergadura actual que atraviesa la humanidad y que golpea directamente las operaciones del Estado, sin duda es el denominado - de forma políticamente correcta -: cambio climático. Como bien lo señala Klein (2015) en su crítica a los negacionistas de este proceso: "Algunos activistas climáticos han tratado de convencer a los negacionistas para apartarlos de sus endurecidas posturas tratando de hacerles entender que, retrasando la acción climática, solo se conseguirá que las intervenciones estatales necesarias sean más extremas" (p. 77).

La misma Klein acepta que, hasta para las izquierdas resultaría molesta una intervención extrema del Estado, una especie de fascismo verde. Pero lo cierto del caso es que, el problema del calentamiento global ha sido siempre presentado en términos de su temporalidad: para prevenirlo o desacelerarlo, para variar los ritmos de emisión de gases de efecto invernadero hasta su reducción total o al menos sostenible, para establecer líneas temporales prospectivas sobre la aparición de los efectos en nuestras vidas cotidianas.

Por esta razón, las consecuencias también son expuestas en términos de tiempo: "Cuanto más esperemos, más castigo se acumula y más drásticamente debemos cambiar para disminuir los 
riesgos del calentamiento global catastrófico" (Klein, 2015, p. 79). El que las narrativas varíen sobre los tipos de intervención política ante el proceso de calentamiento global, no modifica en lo absoluto que, este problema social sobre el ambiente se encuentra saturado por su componente temporal.

Lo anterior es expresado por Malm (2016) en su idea de la venganza del tiempo: "Wherever we look at our changing climate, we find ourselves in the grip of the flow of time." (Malm, 2016, 14). El cambio climático nos recuerda que: 1) somos presas del tiempo, 2) la incapacidad del modo de producción capitalista para generar una economía sostenible con el ambiente y 3) la correlación de fuerzas internacionales muestra la tendencia de los Estados centrales del capital (Estados Unidos, Rusia y China) a no realizar ningún cambio fundamental en el modo de producción y la lógica de acumulación de capital, aunque eso conduzca a un colapso ambiental-civilizatorio.

Lo anterior, torna imperativo el cambio del modelo de civilización que tenemos, porque de lo contrario enfrentamos nuestra propia extinción; sin embargo, el capitalismo contiene una lógica contraria a dicho imperativo: en lugar de desacelerar, acelera la acumulación del capital y con ella, la destrucción del medio ambiente y la emisión de gases contaminantes a la atmósfera.

Precisamente, los trabajos de Angus (2016) y Bonneuil y Fressoz (2016) dan cuenta de que, a mediados del siglo XX, la humanidad experimentó un proceso conocido como La Gran Aceleración. A diferencia de toda la historia humana anterior, los últimos setenta años dan cuenta de una incomparable interferencia, acelerada y extensiva, sobre la naturaleza, haciendo irreversible el daño ocasionado a la diversidad de la vida en la Tierra. Algunas prácticas humanas exacerbadas por el proceso de acumulación de capital como: la deforestación, el uso de cada vez mayores extensiones de tierra para el cultivo, el incremento de nitrógeno en la atmósfera por uso de fertilizantes, el uso insostenible de agua para la agricultura, el incremento en la concentración de dióxido de carbono en la atmósfera por los combustibles fósiles, la ampliación de conflictos geopolíticos y la carrera armamentística, entre otros; son los causantes de este proceso.

Y esto ha sucedido porque el capitalismo, como señala Malm (2016) guarda una relación de correspondencia con una forma específica de energía: los combustibles fósiles. Esto explica su dependencia e incluso, ante la posibilidad real de generar un cambio en los tipos de energía para satisfacer las necesidades humanas, la renuencia por realizar tales procesos de transición.

No es de extrañar que Malm (2016) recurra a la metáfora del tren que no puede detenerse y por el contrario, siempre acelera aunque se encuentre cerca del precipicio. El progreso capitalista conduce de forma acelerada a la caída en el precipicio, dejando a su paso una vorágine de catástrofes y ruinas.

Las regulaciones de los Estados son, en este aspecto, altamente diversas e inefectivas, siempre que se desarrollen dentro de los límites de la lógica y dominio del capital. Vale la pena recordar en este punto al joven Marx (2008) decir: "todos los Estados buscan la causa en deficiencias causales o intencionales de la administración y por ello buscan el remedio a todos sus males en medidas administrativas. ¿Por qué? Justamente porque la administración es la actividad organizadora del Estado" (p. 123). 
Las palabras aclaradoras de Marx nos recuerdan que, los problemas ocasionados por la fractura metabólica no son un asunto estrictamente político ni administrativo, sino que son elementos constituyentes del capitalismo, de modo que son infranqueables para éste. Por esta razón, a pesar de que se obtengan victorias por parte de los movimientos sociales y ambientalistas en distintos países, la tendencia global apunta a la destrucción paulatina de la naturaleza, en la medida que la lógica de acumulación de capital no sea superada.

Actualmente, los movimientos ambientales e indígenas surgen como los principales adversarios de dicha lógica al proponer una alternativa al sistema de dominación capitalista. Esto es importante de mencionar porque, como señala Hirsch (1996), incluso los movimientos obrero-sindicales han pactado con la burguesía en detrimento del ambiente:

\begin{abstract}
las crisis económicas pudieron ser negociadas mediante la manipulación económica y administrativa; por ejemplo, mediante el traslado de las crisis de realización dentro de la esfera de la reproducción. Así, se podría mencionar la avanzada destrucción de la naturaleza y el medio ambiente con la ayuda del Estado a fin de abordar lo tocante a los rentables cambios en la tecnología de la producción. Esta estrategia fue apoyada por los sindicatos, en tanto esto garantizaba una base para negociaciones de mayores salarios. La pregunta concerniente a la totalidad de las condiciones materiales de existencia estaba, por tanto, excluida. Los sindicatos habían probado ser importantes gestores auxiliares en aplicar el modelo fordista de producción y reproducción (p. 32).
\end{abstract}

No necesariamente el movimiento obrero ha sido consciente ni posee las herramientas para analizar la totalidad de las condiciones materiales. Puede observarse que, a cambio de una reivindicación eminentemente económica (una lucha economicista), se deja de lado el análisis de las condiciones naturales, indispensables para su propia reproducción vital.

Así mismo, esta situación pone de manifiesto la complejidad de las relaciones y estrategias entre actores en una determinada escena política, la cual, no puede ser analizada simplemente desde la lógica de enfrentamiento de dos clases antagónicas abstractas, sino que, demanda el ejercicio de identificación y análisis de los distintos grupos que conforman el campo de la política y cómo se relacionan y posicionan con determinados proyectos de sociedad.

De ahí, la necesidad, apuntada por Burkett y Foster, de retornar a la lectura de Marx y encontrar las claves para comprender el surgimiento de los problemas ecológicos contemporáneos a través de la fractura metabólica y el proceso de valorización del capital. Todos los movimientos sociales anticapitalistas tendrían que integrar este marco categorial para comprender una de las contradicciones neurálgicas de las sociedades capitalistas y, a partir de ahí, configurar estrategias y tácticas políticas según coyunturas.

Ahora bien, como decía, según la correlación de fuerzas, así el Estado capitalista amplía o disminuye los alcances de sus regulaciones. Por ejemplo, puede prohibir el uso de ciertas prácticas económicas como la minería a cielo abierto; o restringir su ejecución como ocurre con ciertos tipos de cacería de animales o la pesca. También regula el establecimiento de zonas de protección como reservas y parques nacionales, con el fin de conservar recursos como el aire, los bosques, el agua y las especies que habitan en los ecosistemas protegidos a nivel legal, o puede establecer medidas regresivas en términos de la ampliación de las tierras de cultivo, ganadería o explotación de recursos dentro de tierras antes protegidas. En ello, pueden darse dinámicas tanto intra-estatales como inter-estatales. 
Importa hacer algunas aclaraciones sobre esto último. Siguiendo a Jessop (2017), el Estado reorganiza las relaciones sociales en el espacio-tiempo, entendiendo el espacio como un objeto de gobernanza en múltiples escalas, las cuales van desde los cuerpos hasta dimensiones planetarias y extraplanetarias.

Ahora bien, el Estado opera además en territorios, es decir, en unidades políticas demarcadas y delimitadas, como indica Jessop (2017), a través de las cuales controla relaciones sociales. La cuestión decisiva de la formación de un Estado, según el autor, consiste en "la capacidad de extender el control territorial mediante la logística del distanciamiento espaciotemporal y mediante la burocratización de una autoridad central” (Jessop, 2017, p. 189).

Para Jessop (2017), el control territorial directo de espacios económicos dispersos y múltiples puede ser costoso. Esto puede demostrarse empíricamente con los efectos a mediano plazo experimentados por el gobierno estadounidense en sus intervenciones militares en distintos países del medio oriente para el control de sus recursos naturales. En menos de 20 años había abandonado gran parte de esta empresa de ocupación militar directa.

Los Estados hacen guerras para colonizar nuevos territorios y extraer de ellos sus recursos naturales, en este sentido, ensanchan sus fronteras territoriales; pero esto no significa que permanezcan con el control del territorio de forma permanente; sino que lo hacen solo el tiempo necesario para destruir ciertas dinámicas económico-político-culturales de la zona que puedan afectar los procesos de explotación de recursos y mano de obra. Después de eso, dejan sociedades fracturadas y destruidas como Afganistán o Irak o el continente africano después de los procesos independentistas en contra de los países centrales de Europa occidental.

Otra vía a la que recurren los grandes Estados imperialistas es la realización de negociaciones con las élites económicas de los países periféricos, apropiándose de concesiones para la explotación de recursos naturales a bajo costo fuera de sus territorios. Buena parte de la historia de América Latina, hasta la actualidad, se mueve en este registro. De por medio se encuentra también el robo y saqueo del campesinado de los países periféricos e incluso de ciertos terratenientes locales que pierden su posición estratégica en el poder político, la cual, es siempre contingente y coyuntural, muy a pesar de los propios capitalistas que danzan también en la lógica depredatoria del capital.

El retroceso en políticas de protección de ecosistemas también reconfigura las dimensiones territoriales internas de los Estados. El avance de la acumulación de capital es infinito y demanda la destrucción y absorción de fuentes de energía que, en otro momento, habían sido protegidas. De ahí la invasión constante a territorios indígenas por todo el mundo y la resistencia de éstos.

En efecto, Marx había mostrado en su tiempo esta dinámica expansiva del capital a nivel espacioterritorial. Los efectos centrales de la fractura metabólica se expresan con total nitidez en este problema: no sólo se trata de la concentración de los títulos de propiedad en cada vez menos manos (los países centroamericanos son un buen ejemplo de la alta concentración de la tierra en un puñado de familias); sino también, del surgimiento de una nueva forma de organización del espacio (la ciudad) en detrimento de la forma existente (el campo); siendo la primera, el espacioterritorio que concentra en las sociedades capitalistas, la mayor parte de los bienes y servicios económicos, sociales, políticos y culturales existentes. 
Por el contrario, cada vez más son las zonas rurales abandonadas ante la falta de acceso a bienes y servicios que hacen inviable la permanencia de personas ahí. Hablamos de un crecimiento desigual y combinado a lo interno de los límites espacio-territoriales del Estado como producto de la fractura metabólica.

En cuanto a las relaciones internacionales, esta distribución desigual de la riqueza y acceso a mercados de trabajo, bienes y servicios, constituye enormes flujos migratorios por parte de la población empobrecida de los países periféricos hacia las urbes de los países centrales del capitalismo o bien, hacia las urbes de países periféricos menos empobrecidos.

Aquí, los Estados receptores de los flujos migratorios y por supuesto, los dueños del capital (fabril y agrícola principalmente), disponen de una fuente de energía vital y mano de obra que puede ser mejor explotada por su vulnerabilidad, mediante una elasticidad relativa y - conveniente al mercado - de los límites del Estado-nación, al mismo tiempo que, constituyen estrategias discursivas y simbólicas para responsabilizar a dichos grupos de los males que el propio modo de producción genera (violencia, saturación de los servicios de asistencia social, delincuencia, etc.). Marx (1974) había visto este problema, al mostrar cómo los grandes industriales ingleses fomentaban el odio entre los obreros ingleses y los irlandeses.

De esta manera, los Estados no sólo constituyen límites geográfico-políticos, sino también, contribuyen con ello, a la constitución de límites simbólico-discursivos entre su población, fragmentándola, con el objetivo de conservar y sostener la dinámica social de explotación y distribución desigual de la riqueza generada.

Mientras tanto, en el marco de la explotación de recursos naturales, las colonias experimentan procesos similares, pero en niveles de desarrollo diferenciados, por su condición de subordinación respecto de los países imperialistas. Por ejemplo, Burkett y Foster (2016) hacían mención de la importación de guano de Perú por parte de Inglaterra como fertilizante para la explotación intensiva de sus suelos; sin embargo, para inicios del siglo XX, el guano había sido sobreexplotado en Perú. Este es un buen ejemplo de la lógica depredatoria del capital.

Igual sucede con los combustibles fósiles o el agua, elementos que constituyen el motor de las guerras imperialistas contemporáneas en contra de los países periféricos que poseen este tipo de recursos: países de Medio Oriente o Venezuela, han sido los principales objetivos especialmente por sus yacimientos de petróleo en los años recientes, como demuestran Tablada y Hernández (2004).

Todas estas guerras conducen no sólo a reconfiguraciones territoriales, tanto externas como internas a los Estados, sino cambios abruptos en el espacio debido a las intervenciones militares y bombardeos. Los daños ambientales y sociales ocasionados por estos actos son irreparables a corto plazo.

En este sentido, el Estado capitalista posee un papel determinante en la modificación de los límites espacio-territoriales y los usos que se dan a dichos espacios, afectando consecuentemente la dinámica de las relaciones sociales que en ellos se desarrollan, por ende, genera cambios en la fisonomía socio-espacio-territorial de los países. Si dichos cambios suceden para proteger o para destruir los espacios-territorios, esto es un resultado dictado por la correlación de fuerzas nacionales e internacionales. 
De ahí la importancia, como señala Jessop (2012), de que las luchas locales que, actualmente encabezan los movimientos por el medio ambiente, puedan dar un salto cualitativo para convertirse a sí mismas en luchas globales. Esto porque, la cuestión ecológica es sistémica y su resistencia reducida al plano de lo local, únicamente podrá resistir de forma temporal.

\section{Conclusiones}

Para Marx, el Estado ocupa un papel central a lo largo del origen del capitalismo. En este sentido, la mediación del Estado es indispensable para comprender la fractura metabólica producida por el capitalismo al vínculo existente entre los seres humanos y la naturaleza.

Dicha fractura contó con la mediación del Estado a través de la implementación de leyes que protegían y legitimaban las acciones de la nueva clase dominante; al mismo tiempo que ejecuta acciones de violencia y contención del conflicto en contra de las amplias masas de trabajadores expropiados de sus tierras.

Conforme la agudización de los conflictos de clase, el Estado también ha desempeñado un papel fundamental en la regulación de la vida humana y la naturaleza. Las contradicciones fundamentales del capitalismo: capital/trabajo y capital/naturaleza, demandan de un actor aparencialmente externo al conflicto para equilibrar y sostener el orden establecido.

Para ello, el Estado configura una serie de políticas que, según la correlación de fuerzas entre las clases en disputa, apuntan a la protección y preservación de las condiciones indispensables para la reproducción de la vida humana y la naturaleza, o al aceleramiento de su destrucción con el fin de potenciar el crecimiento acelerado de las ganancias del capital.

De ahí que se desarrollen operaciones políticas sobre la temporalidad-corporeidad de los individuos y sobre la temporalidad-territorialidad de la naturaleza. La intervención del Estado es indispensable en estas materias; ya que, de lo contrario, si la economía capitalista operara de manera unilateral, habría desembocado en el uso permanente de la violencia por parte de la clase burguesa y, en consecuencia, al final de su ordenamiento social.

\section{REFERENCIAS}

Angus, I. (2016). Facing the Anthropocene. Fossil Capitalism and the Crisis of the Earth System. Monthly Review Press.

Antunes, R. (2009). Diez tesis sobre el trabajo del presente (y el futuro del trabajo). En J. Neffa, E. Garza, y E. Muñiz. (Eds.). Trabajo, empleo, calificaciones profesionales, relaciones de trabajo e identidades laborales. (pp. 29-44) CLACSO

Antunes, R. (2015). Los modos de ser de la informalidad: ¿hacia una nueva era de la precarización estructural del trabajo? Ecuador Debate, 94, 69-79.

Bonneuil, C., \& Fressoz, J. (2016). The Schock of the Anthropocene. The Earth, History and Us. Verso.

Burkett, P., \& Foster, J. (2016). Marx and the Earth. Brill.

Castel, R. (1997). La metamorfosis de la cuestión social: una crónica del salariado. Paidós

Foster, J. (2000). La ecología de Marx. Materialismo y naturaleza. El Viejo Topo. 
Foster, J., \& Magdoff, F. (1998). Liebig, Marx and the Depletion of Soil Fertility: Relevance for Today's Agriculture. Monthly Review, 50(3), 43-6o. https://doi.org/10.14452/MR-050-03-1998-07_3

Foucault, M. (2001). Defender la sociedad. Fondo de Cultura Económica.

Han, B. (2012). La sociedad del cansancio. Herder.

Hirsch, J. (2005). ¿Qué significa Estado? Reflexiones acerca de la teoría del Estado Capitalista. Revista de Sociologia e Política, 24, 165-175. https://revistas.ufpr.br/rsp/article/view/3722

Hirsh, J. (1996). Globalización, capital y Estado. Universidad Autónoma Metropolitana Xochimilico.

Hobsbawm, E. (2012). Guerra y paz en el Siglo XXI. Crítica.

Jameson, F. (1989). Documentos de cultura, documentos de barbarie. La narrativa como acto socialmente simbólico. Visor Distribuciones S.A.

Jessop, R. (2008). El futuro del Estado Capitalista. Catarata.

Jessop, R. (2012). Economic and Ecological Crises: Green new deals and no-growth economies. Development, 55(1), 17-24. https://doi.org/10.1057/dev.2011.104

Jessop, R. (2017). El Estado. Pasado Presente Futuro. Catarata.

Jessop, R. (2017a). Poulantzas on political economy, political ecology, and democratic socialism. Journal of Political Ecology, 24, 186-199. https://doi.org/10.2458/v24i1.20794

Klein, N. (2015). Esto lo cambia todo. El capitalismo contra el clima. Paidós Ibérica.

Kohan, N. (2013). Nuestro Marx. Fetichismo y mercancía. La oveja roja.

Maquiavelo, N. (2004). El Príncipe. Ediciones Abraxas.

Marx, K. (1974). Extracto de una comunicación confidencial. En, Instituto de Marxismo-Leninismo (eds.). C. Marx y F. Engels. Obras Escogidas. II. (pp. 84-187) Progreso.

Marx, K. (2008). Glosas marginales al artículo "El rey de Prusia" y la reforma social. Por un "prusiano". En R. Jaramillo (ed.). Escritos de Juventud sobre el Derecho. Textos 1837-1847. (pp. 112-133.) Anthropos

Marx, K. (2008a). C. Marx y F. Engels, 2 de abril 1858. Cartas sobre el tomo I de “El Capital”. En, R. Wenceslao. (Ed.). El Capital. Crítica de la economía política (Tomo I). Fondo de Cultura Económica

Marx, K. (2012). Los Manuscritos de París. En J. Muñoz (comp.). Marx. (pp. 433-572) Gredos.

Marx, K. (2017). El capital. Crítica de la economía política. Tomo 1. Siglo XXI.

Mészáros, I. (2011). Forms of Consciousness. Vol. 2: The Dialectic of Structure and History. Monthly Review.

Osorio, J. (2012). Estado, biopoder, exclusion. Análisis desde la lógica del capital. Anthropos.

Poulantzas, N. (1986). Estado, poder y socialismo. Siglo Veintiuno.

Quastel, N. (2016). Ecological Political Economy: Towards a Strategic-Relational Approach. Review of Political Economy, 28(3), 336-353 https://doi.org/10.1080/09538259.2016.1145382

Saito, K. (2014, October 1). The Emergence of Marx's Critique of Modern Agriculture. Monthly Review. https:// cutt.ly/wWeW8TH

Saito, K. (2017). Karl Marx's Ecosocialism. Capitalism, Nature, and the Unfinished Critique of Political Economy. Monthly Review Press.

Tablada, C. y Hernández, G. (2004). Petróleo, poder y civilización. Popular.

UNI Global (2021). The Amazon Panopticon. A Guide for Workers, Organizers \& Policymakers. UNI Global Union.

Williams, C. (2010). Ecology and Socialism. Haymarket Books. 


\section{AUTOR}

Omar Santiago Herrera Rodríguez. Investigador independiente. Master en Estudios Latinoamericanos con énfasis en Cultura y Desarrollo, por la Universidad Nacional de Costa Rica. Bachiller en Filosofía, por la Universidad de Costa Rica. Estudiante de la Maestría de Filosofía, en la Universidad de Costa Rica.

\section{Conflicto de intereses}

El autor declara que no existe conflicto de interés posible.

Financiamiento

No existió asistencia financiera de partes externas al presente artículo.

Agradecimientos

$\mathrm{N} / \mathrm{A}$ 